\title{
Measuring the acceptability of EQ-5D-3L health states for different ages: a new adaptive survey methodology
}

\author{
Zoltán Hermann $^{1,2}$ (D) Márta Péntek ${ }^{3}$ (D) $\cdot$ László Gulácsi $^{3,4}$ (D) $\cdot$ Irén Anna Kopcsóné Németh ${ }^{5} \cdot Z^{2}$ sombor Zrubka ${ }^{3,4}$ (D)
}

Received: 1 February 2021 / Accepted: 21 December 2021 / Published online: 5 January 2022

(c) The Author(s) 2022

\begin{abstract}
Background Acceptable health and sufficientarianism are emerging concepts in health resource allocation. We defined acceptability as the proportion of the general population who consider a health state acceptable for a given age. Previous studies surveyed the acceptability of health problems separately per EQ-5D-3L domain, while the acceptability of health states with co-occurring problems was barely explored.

Objective To quantify the acceptability of $243 \mathrm{EQ}-5 \mathrm{D}-3 \mathrm{~L}$ health states for six ages from 30 to 80 years: 1458 health state-age combinations (HAcs), denoted as the acceptability set of EQ-5D-3L.

Methods In 2019, an online representative survey was conducted in the Hungarian general population. We developed a novel adaptive survey algorithm and a matching statistical measurement model. The acceptability of problems was evaluated separately per EQ-5D-3L domain, followed by joint evaluation of up to 15 HAcs. The selection of HAcs depended on respondents' previous responses. We used an empirical Bayes measurement model to estimate the full acceptability set.

Results 1375 respondents (female: 50.7\%) were included with mean (SD) age of 46.7 (14.6) years. We demonstrated that single problems that were acceptable separately for a given age were less acceptable when co-occurring jointly $(p<0.001)$. For 30 years of age, EQ-5D-3L health states of '11112' (11.9\%) and '33333' (1\%), while for 80 years of age '21111' (93.3\%) and '33333' (7.4\%) had highest and lowest acceptability (\% of population), respectively.

Conclusion The acceptability set of EQ-5D-3L quantifies societal preferences concerning age and disease severity. Its measurement profiles and potential role in health resource allocation needs further exploration.
\end{abstract}

Keywords Acceptability $\cdot$ EQ-5D $\cdot$ Societal preferences $\cdot$ Priority setting $\cdot$ Sufficientarianism

JEL I10

Márta Péntek

pentek.marta@uni-obuda.hu

1 Institute of Economics, Centre for Economic and Regional Studies, Tóth Kálmán u 4., Budapest 1097, Hungary

2 Institute of Economics, Corvinus University of Budapest, Fôvám tér 8., Budapest 1093, Hungary

3 Health Economics Research Center, Óbuda University, Bécsi út 96/b, Budapest 1034, Hungary

4 Corvinus Institute for Advanced Studies, Corvinus University of Budapest, Fơvám tér 8., Budapest 1093, Hungary

5 Department of Infection Control, Medical Centre, Hungarian Defence Forces, Róbert Károly körút 44., Budapeset 1134, Hungary

\section{Background and aims}

The quality-adjusted life-year (QALY), by combining both the quality and length of life in a single figure became a key measure of health gains in health economic analyses [1]. For the measurement of the quality-of-life component of QALYs, the EQ-5D instrument is preferred in many countries [2]. EQ-5D describes distinct health states, to which societal preferences (utility scores) are attached to quantify quality-of-life [3, 4]. Utility scores are elicited in valuation studies via methods that are rooted in multi-attribute utility theory, such as time-trade-off or discrete choice, which involve choices between different durations spent in full health or various disease states [2-5].

A salient feature of QALYs is their measurement invariance concerning the severity of disease and age, described 
by the catchy phrase "a QALY is a QALY is a QALY" [6]. However, in case of similar QALY gains, in scarce-resource settings, people prefer to treat more severe patients over less severe ones and young adults over older ones [7, 8]. Despite their simplicity and widespread use [9], QALYs do not reflect adequately these and several other preferences that matter in decision-making $[9,10]$. To overcome these limitations, numerous improvements and alternative frameworks have been proposed $[11,12]$.

The normative background for using acceptable health in resource allocation has been explored by Wouters et al. [13], building on the sufficientarian theory of distributive justice [14]. The concept of acceptable health is based on the finding that people consider certain health problems increasingly acceptable for older ages as a normal consequence of aging [15-17]. The main idea is that the treatment of individuals in not acceptable health would enjoy priority over treating those who are in acceptable health states, while the goal would be to ensure acceptable (but not necessarily perfect) health for all $[13,18]$.

Acceptability and utility scores are both theoretically and quantitatively different measures of health. Although not based on standard economic theory, acceptability has been used as a measurable rating for a complex set of subjective judgements [19], such as the overall "goodness" of a health state. Measuring acceptability via binary yes/no questions carries as much information about a population's judgements as continuous measures [20]. As opposed to valuation studies [4], the evaluation of acceptability does not involve choices concerning risk, no trade-off as well as no imaginations about death or different time perspectives are involved. However, instead of attaching a single utility value to a health state, acceptability of a health state is measured in different ages. Throughout this paper, the term "acceptable health" will refer to the general concept, while "acceptability" will denote a measure: the proportion of the general population, who consider a certain health state or problem acceptable for (people in) a given age. We also note that acceptability of a health state is conceptually different from the acceptability of a health intervention [21].

Acceptable health has been measured via the EQ-5D-3L instrument in several studies [15-17, 22]. EQ-5D-3L describes three levels of problems in five health domains [3]. Although EQ-5D-3L has gradually been replaced by the five-level (EQ-5D-5L) version due to its more favourable psychometric properties [23], immense experience has been gained with EQ-5D-3L in general population surveys and clinical studies [24, 25] and its 243 health states are better suited for the evaluation of acceptability than the 3125 health states described by EQ-5D-5L.

Using traditional survey methods, the direct measurement of the acceptability of all EQ-5D-3L health states for several ages would require prohibitively large samples or long questionnaires. Therefore, initial studies assessed the acceptability of problems separately in each of the five health domains. Via this method, the acceptability of all EQ-5D-3L health states could only be deduced if assuming that either (1) joint problems in multiple health domains were not acceptable at all or (2) separately acceptable problems were also acceptable when co-occurring jointly. However, these two assumptions led to rather divergent results, so the acceptability for all EQ-5D-3L health states could not be estimated accurately so far [15-17].

The primary aim of this paper is to measure the acceptability of all 243 EQ-5D-3L health states at 30, 40, 50, 60, 70 and 80 years of age in the Hungarian general population and develop an acceptability set for EQ-5D-3L. To estimate the acceptability of health states with problems in multiple health domains, we have developed an adaptive survey methodology and a matching statistical measurement model and tested whether this method delivers more accurate acceptability estimates compared to the assumption that separately acceptable problems are also acceptable when co-occurring jointly.

\section{Methods}

\section{Data}

We performed a cross-sectional online survey in May 2020 using quotas proportional to the $\geq 18$-year-old general population in terms of age, gender, education and geographical region. We planned to recruit 1200 respondents. Participation was voluntary and anonymous, and participants gave their written informed consent prior completing the questionnaire. Our study was approved by the Ethical Committee of the Medical Research Council of Hungary (ETT TUKEB; 3857-5-2019/EKU). Data were collected by a market survey company, no compensation was given for participating in the study.

\section{Measuring acceptability}

Measuring the acceptability of health states with problems in multiple health domains is a stepwise process that involves (1) the selection of potential survey questions and (2) conducting an adaptive survey to boost the information content of collected data and then (3) estimating acceptability via a statistical measurement model that mitigates the bias resulting from the adaptive survey design. The key steps of this method are summarized in Fig. 1. 
Fig. 1 The process of measuring acceptability

\section{Step 1}

Defining and selecting survey questions

Defining 1458 health state-age combinations (HAcs)

$243 E Q-5 D-3 L$ profiles $x 6$ ages $(30,40,50,60,70,80$ years)

Selecting 750 HAcs for the joint evaluation phase of the adaptive survey

Based on previous research, 708 HAcs are excluded due to near-zero expected acceptability.

\section{Step 2}

Data collection via an adaptive survey

Separate evaluation

Respondents separately evaluate the acceptability of problems in each EQ-5D-3L domain.

Joint evaluation

Each respondent evaluates a random sample of potentially acceptable HAcs provided by the adaptive survey algorithm, based on the respondents previous responses.

\section{Step 3}

Estimating acceptability

Potential acceptability of each HAc (method: population proportion)

The acceptability of HAcs after separate evaluation, assuming that all separately acceptable problems are also acceptable when co-occurring jointly.

Conditional acceptability of each HAc (method: empirical Bayes statistical model)

The proportion of respondents accepting a certain HAc after joint evaluation, under the condition that it is potentially acceptable for the respondent.

Acceptability of each HAc (the product of potential and conditional acceptability)

\section{Selecting potential survey questions}

We evaluated acceptability using the EQ-5D-3L instrument [3]. The descriptive system of EQ-5D-3L assesses selfreported health in five domains: mobility, self-care, usual activities, pain/discomfort and anxiety/depression. In each dimension, respondents can describe their health as having: no problems (1), some problems (2) or severe problems (3), providing $243\left(3^{5}\right)$ distinct health states [3]. EQ-5D-3L health states are denoted with 5-digit numbers indicating the problem levels in the five domains (e.g., 21,131 represents moderate problems with mobility and severe pain/discomfort). The EQ-5D-3L index is a utility value attached to a health state that reflects average preferences of the general population so that 1 denotes perfect health, 0 denotes death and negative values denote worse-than-dead health states. A value set comprises the index values of all 243 health states. To compare our results with previous studies, we applied the Dutch value set $[16,26]$.

To measure acceptability, we estimated the proportion of respondents who considered an EQ-5D-3L health state acceptable for ages $30,40,50,60,70$ and 80 years. We will denote a health state - age combination (HAc) with a subscript of age attached to the EQ-5D-3L health state (e.g., $\left.12113_{50}\right)$. Altogether, we used 1458 HAcs (243 EQ-5D-3L health states $\times 6$ ages) and denoted the full set of acceptability estimates attached to them as the EQ-5D-3L acceptability set. While we defined the acceptability of a HAc as a proportion, in case of a given respondent, acceptability of a HAc will refer to the result of a binary yes / no evaluation.

From the 1458 HAcs, we preselected 750 items with multiple health problems for joint evaluation. We will denote these HAcs as the JE frame. By narrowing the question pool to the JE frame, we aimed to increase the precision of acceptability estimates. Also, respondents were allocated to predefined random question sequences of the JE frame, which allowed the mitigation of bias that resulted from the adaptive survey design (see below). The JE frame excluded 642 HAcs, that were almost universally rated as not acceptable in previous research [17], 60 HAcs that contain problems in only one domain and 6 HAcs denoting full health (see Online Resource 1). Although not all HAcs were included in the JE frame, the acceptability was estimated for all 1458 HAcs. 


\section{Acceptability survey questions and the adaptive survey algorithm}

The acceptability survey comprised two stages. First, respondents were asked from what age onwards they considered moderate or severe problems acceptable in each EQ-5D domain. The response options were 30, 40, 50, 60, 70 and 80 years of age or never. The sample question is depicted in Fig. 2A. Previous studies evaluated acceptability using the same question format, albeit the age range varied [15, 16, 22, 27]. As the acceptability of health problems was evaluated separately per EQ-5D-3L domain, we will refer to this part of the survey as separate evaluation (SE).

In the second stage of the survey, respondents evaluated HAcs with multiple problems as either acceptable or not acceptable (Fig. 2B). Depending on the answers in SE, up to 15 semi-random questions were selected by an adaptive survey algorithm. Since the acceptability of co-occurring health problems in HAcs was evaluated jointly by respondents, this part of the survey is denoted as joint evaluation (JE).

The idea of the adaptive survey algorithm is that due to the ordinal structure of EQ-5D-3L response levels, by knowing the acceptability of a HAc, the acceptability of numerous other HAcs can be deduced for a given respondent, narrowing the set of questions that can contain additional information for the elicitation of his or her preferences.

This deduction builds on two main assumptions. The first assumption is consistency: as EQ-5D-3L dimensions are ordinal measures or health, if a health state is acceptable, then all health states that contain only the same or lower

\section{A separate evaluation (SE)}

Mobility

Can you please indicate from which age onwards you consider problems with mobility acceptable?

Age (years)

70 From 50 From 60 From 70 From 80 Never onwards onwards onwards onwards onwards onwards

\begin{tabular}{llllllll}
\hline $\begin{array}{l}\text { Some problems } \\
\text { walking about }\end{array}$ & $\square$ & $\square$ & $\square$ & $\bigotimes$ & $\square$ & $\square$ & $\square$ \\
\hline Confined to bed & $\square$ & $\square$ & $\square$ & $\square$ & $\square$ & $\bigotimes$ & $\square$ \\
\hline
\end{tabular}

B Joint evaluation (JE)

Based on your previous answers, we would like to know if you consider some persistent health problems acceptable for a given age.

Please imagine the following age and health state and indicate if acceptable or not. For 70 years of age, persistently, on average
Some problems in walking about

No problems with washing or dressing oneself Some problems with performing one's usual activities Having moderate pain or discomfort
Not being anxious or depressed

Fig. 2 Sample questions of the adaptive survey levels of health problems (denoted as better health states) are also assumed to be acceptable for a given age. If a health state is not acceptable, then all health states that contain only the same or greater levels of problems (worse health states) are not acceptable either for a given age. However, no inferences can be made about two health states that contain both higher and lower problem levels in any domains of the EQ-5D-3L. The second assumption is monotonicity in age: if a health state is acceptable for a certain age, then we consider the same or better health states acceptable for older ages as well. At the same time, if a health state is not acceptable for a certain age, inferences can be made about the non-acceptability of the same or worse health states for younger ages.

After the SE stage of the survey, 60 HAcs with a single health problem (e.g., $21111_{60}$ ) could be classified as acceptable or unacceptable for each respondent. The remaining HAcs with multiple health problems could be labelled as either unacceptable or potentially acceptable using the assumptions above. Those HAcs, which contained unacceptable problem levels in any domain could be categorised as not acceptable. However, the joint acceptability of cooccurring problems remained unknown for those HAcs (e.g., $21122_{60}, 21121_{60}, 21112_{60}$ or $11122_{60}$ ), which included combinations of problems that were acceptable one by one during SE (e.g., $21111_{60}, 11121_{60}, 11112_{60}$ ). We denoted these HAcs as potentially acceptable. Only potentially acceptable HAcs were subject to joint evaluation.

The set of potentially acceptable HAcs varies depending on respondents' preferences, but it is generally too large for an all-encompassing evaluation in a survey situation. The adaptive survey algorithm aims to maximise the obtained information about the unique preference profile of respondents using no more than $15 \mathrm{JE}$ questions per respondent, while maintaining a structure that allows unbiased acceptability estimation for each HAc. The following paragraphs introduce the main steps of the JE procedure. Details are provided in the Online Resource 2.

First, one of the 50 predefined HAc sequences of the JE frame was allocated to the respondent. The actual JE questions of the respondent were selected from the potentially acceptable HAcs of the JE frame. Starting with the first potentially acceptable HAc in the sequence, the respondent was asked to evaluate it. Then the algorithm moved to the next potentially acceptable HAc, and its acceptability was either deduced from prior responses (indirect evaluation) or the respondent was subsequently asked to evaluate it directly. The algorithm stopped when the respondent had answered 15 questions or all potentially acceptable HAcs had been evaluated via less than 15 questions.

Altogether, by moving along the predefined sequence, each respondent directly or indirectly evaluated a subset of $k$ HAcs, which we denote as the JE response set. The JE 
response set is a random sample of potentially acceptable HAcs evaluated as acceptable or not acceptable, with a sample size varying by each respondent.

\section{Statistical measurement model}

As the number of jointly evaluated HAcs depends on respondents' preferences, the sheer proportion of respondents who accept a HAc would lead to biased acceptability estimates (see Online Resource 3). Therefore, we estimate acceptability using a statistical measurement model, which mitigates bias and provides acceptability estimates for HAcs that were not included in the JE frame.

First, we decompose the acceptability $\left(\mathrm{A}^{\mathrm{j}}\right)$ of a given HAc (denoted as $\mathrm{HAc}^{\mathrm{j}}$, such as $12123_{50}$ ) into the product of its potential acceptability $\left(\mathrm{PA}^{\mathrm{j}}\right)$ and conditional acceptability $\left(\mathrm{CA}^{\mathrm{j}}\right)$ as shown in Eq. (1). $\mathrm{PA}^{\mathrm{j}}$ refers to the proportion of the population who consider each health problem of $\mathrm{HAc}^{\mathrm{j}}$ separately acceptable for the given age. $\mathrm{CA}^{\mathrm{j}}$ denotes the estimated proportion of respondents who jointly evaluate $\mathrm{HAc}^{\mathrm{j}}$ as acceptable, given that $\mathrm{HAc}^{\mathrm{j}}$ is potentially acceptable for them. $\mathrm{CA}^{\mathrm{j}}$ is estimated from the JE response set, since $\mathrm{HAc}^{\mathrm{j}}$ is evaluated by a given respondent only if it is potentially acceptable after SE.

$A^{j}=P A^{j} \times C A^{j}$

The two terms are estimated using two different methods. From the complete dataset after SE (1458 HAcs for all respondents), the first term, PA is estimated directly as the proportion of respondents potentially accepting the given HAc. Estimates are adjusted by post-stratification weights to correct for sampling error (see below).

CA is estimated from an incomplete dataset, since not all potentially acceptable HAcs can be evaluated via 15 questions by all respondents in JE. Moreover, JE responses are unevenly distributed across HAcs. Those HAcs, which are potentially acceptable for many respondents (e.g., mild problems in older ages), have plenty observations, while other HAcs with low potential acceptability (e.g., severe problems in younger ages) receive only few or even zero JE responses. To minimize prediction error in this unbalanced data structure, $\mathrm{CA}^{\mathrm{j}}$ is estimated using an empirical Bayes strategy by combining the direct acceptability estimates and regression model-based parametric estimates. To reduce the mean square error of prediction, the empirical Bayes or shrinkage approach optimally balances the measurement error of direct estimates of $\mathrm{CA}^{\mathrm{j}}$ from the JE response set of each respondent and model error of parametric estimates of $\mathrm{CA}^{\mathrm{j}}$ from the combined JE response of all respondents [28, 29]. For technical details see Online Resource 3.

$\mathrm{CA}^{\mathrm{j}}$ is estimated by weighted ordinary least squares (OLS) regression, where weights are the products of two components: (1) a population weight (post-stratification weights to correct for sampling error) and (2) an information weight to correct for the bias arising from the unbalanced data structure of JE responses. We compare two models and select the one with better fit based on Akaike's information criteria (AIC) [30], Schwarz's Bayesian information criteria BIC [31] and likelihood ratio test results. Model $1\left(\mathrm{M}_{1}\right)$ is specified as the one used for estimating UK time-trade-off utility values in the MVH study: the predictors include moderate and severe problem levels in each EQ-5D-3L domain and an N3 term for the presence of any severe problems [7]. In addition, the predictors of Model 2 (M2) include dummy variables denoting different levels of PA. For technical details, see Online Resource 4.

As a final step, we calculate acceptability $\left(A^{j}\right)$ for each HAc according to Eq. (1). The exceptions are 60 HAcs with a single health problem (e.g., $21111_{30}, 21111_{40} \ldots 11113_{80}$ ). These HAcs are not evaluated jointly, and their acceptability is estimated from SE responses as a population proportion like PA. Furthermore, by definition, the acceptability of full health $\left(1111_{30-80}\right)$ is 1 for any age.

\section{Auxiliary analyses}

In addition to quantifying an acceptability set for EQ-5D-3L, we also performed auxiliary analyses.

\section{Descriptive statistics}

We applied unweighted descriptive methods to summarize sample characteristics and components of the statistical measurement model. The association between acceptability and PA as well as acceptability profiles of selected HAcs over age were shown graphically.

\section{Assessment of data quality}

As a signal of respondent effort, we measured response time during the JE task and excluded respondents whose mean response time per question was too short $(\leq 8 \mathrm{~s})$ to comprehensively read questions before answering. Details are provided in the Online Resource 5.

Since the JE frame was established using PA estimates of external research [17], to verify its applicability, we calculated the absolute agreement between HAcs included and excluded from the JE frame and those 750 HAcs with multiple problems, which had greatest and 708 HAcs with lowest PA measured in our study.

In EQ-5D-3L valuation studies, logically inconsistent responses (i.e., valuation results that contradict the logical order of health states) were explored and included in the estimation samples in varying proportions [32-36]. However, indirect evaluation in JE automatically provides all possible 
logically consistent answers, so responses to direct questions cannot be inconsistent, not even from a "random" responder. Therefore, to assess the "truthfulness" of answers, respondents directly evaluated 5 fixed HAcs after JE as control questions and we calculated the absolute agreement between responses to JE questions (direct and indirect evaluations) and the control questions.

\section{Comparing results with previous research}

JE was applied first in this study, but given the similar sampling strategies, we compared our SE results with those of the Netherlands [16] as follows. Prior studies summarised SE results by assuming that separately acceptable problems were also acceptable when co-occurring jointly. For each respondent, the highest levels of acceptable problems for the six ages were aggregated as acceptable HAcs. The sample mean of the EQ-5D-3L index scores of these HAcs in each age was denoted as the aggregate acceptable health curve $\left(\mathrm{AHC}_{\text {aggregate }}\right)$ [15-17]. We graphically compare the $\mathrm{AHC}_{\text {aggregate }}$ of our sample with that of the Netherlands using Dutch EQ-5D-3L index values [26].

Finally, we formally tested the hypothesis whether adding CA estimates in the statistical measurement model (and conducting JE) improves the accuracy of acceptability estimates compared to using PA estimates (and conducting SE) alone. According to Eq. (1), if separately acceptable problems are also acceptable when co-occurring jointly, then $\mathrm{CA}^{\mathrm{j}}=1$ for all $\mathrm{j}$. We tested the assumption that $\mathrm{CA}^{\mathrm{j}}=1$ via Wald test and tested whether $\mathrm{CA}^{\mathrm{j}}$ is a constant across all HAcs via the overall likelihood ratio test of the parametric estimation model of $\mathrm{CA}^{\mathrm{j}}$ (see above). All analyses were performed in Stata 16 statistical software package [37].

\section{Results}

\section{Sample characteristics}

Recruitment was extended to achieve low education quotas, so 1453 individuals provided answers in the survey. Mean (SD) response time per question in JE was 41 (189) seconds, median response time was $21 \mathrm{~s}$. Based on adequate response times, we included $1375(94.6 \%)$ respondents in the analysis sample (hereinafter: sample). Mean (SD) age was 46.7 (14.6) years. The sample was similar to the general population in terms of gender and region, while the $65+$ age group and lower education group was under- and the 50-64 age group and the higher education group was overrepresented (Table 1).

\section{The components of acceptability}

\section{Acceptability of problems in separate evaluation}

The acceptability of problems increased steeply beyond 50 years of age in all EQ-5D-3L domains. The acceptability of problems in the anxiety / depression domain was
Table 1 Sample demographic characteristics

\begin{tabular}{|c|c|c|c|c|c|c|}
\hline & & \multicolumn{2}{|c|}{ Sample } & \multicolumn{2}{|c|}{ Survey } & \multirow{2}{*}{$\begin{array}{l}\text { Population } \\
\%\end{array}$} \\
\hline & & $N$ & $\%$ & $N$ & $\%$ & \\
\hline \multirow[t]{2}{*}{ Gender } & Women & 678 & 49.31 & 724 & 49.83 & 53.18 \\
\hline & Men & 697 & 50.69 & 729 & 50.17 & 46.82 \\
\hline \multirow[t]{4}{*}{ Age } & $18-34$ & 350 & 25.45 & 384 & 26.43 & 23.25 \\
\hline & $35-49$ & 405 & 29.45 & 438 & 30.14 & 28.96 \\
\hline & $50-64$ & 444 & 32.29 & 454 & 31.25 & 24.69 \\
\hline & $65+$ & 176 & 12.80 & 177 & 12.18 & 23.10 \\
\hline \multirow[t]{4}{*}{ Education } & Lower secondary or below (ISCED0-2) & 179 & 13.02 & 187 & 12.87 & 23.21 \\
\hline & Upper secondary: vocational (ISCED3c) & 223 & 16.22 & 240 & 16.52 & 21.89 \\
\hline & Upper secondary: general (ISCED3a,4) & 476 & 34.62 & 500 & 34.41 & 33.14 \\
\hline & Tertiary (ISCED5-6) & 497 & 36.15 & 526 & 36.20 & 21.76 \\
\hline \multirow[t]{7}{*}{ Region } & Central Hungary & 405 & 29.45 & 430 & 29.59 & 30.92 \\
\hline & Northern Hungary & 162 & 11.78 & 173 & 11.91 & 11.42 \\
\hline & Northern Great Plain & 208 & 15.13 & 217 & 14.93 & 14.59 \\
\hline & Southern Great Plain & 184 & 13.38 & 193 & 13.28 & 12.89 \\
\hline & Western Transdanubia & 132 & 9.60 & 137 & 9.43 & 10.14 \\
\hline & Central Transdanubia & 133 & 9.67 & 141 & 9.70 & 10.83 \\
\hline & Southern Transdanubia & 151 & 10.98 & 162 & 11.15 & 9.20 \\
\hline Total & & 1375 & 100.00 & 1453 & 100.00 & 100.00 \\
\hline
\end{tabular}

Source of population data: Micro-census 2016 [46] 
slightly less age dependent, and self-care problems were less acceptable for 60 and 70 years of age than problems in other domains (Fig. 3A).

The number of domains with acceptable problems increased with age. For age 30, 85.3\% (1173/1375), $10.4 \%(143 / 1375)$ and $0.5 \%(7 / 1375)$, while for age 80 , $3.1 \%$ (42/1375), 2.4\% (38/1375) and 57.6\% (792/1375) of respondents considered problems in none, only one and all five EQ-5D-3L domains acceptable, respectively (Fig. 3B). The preferences of respondents were rather heterogenous in SE. Among 1375 respondents we identified 1029 different patterns of acceptable health problems.

\section{Verifying the JE frame}

Online Resource 6 provides the distribution of potential acceptability for two subsets of HAcs. Fig. S5A depicts the distribution for those 642 HAcs that contained multiple problems but were excluded from the JE frame. Their median (range) potential acceptability was 0.006 (0.003-0.035). Fig. S5B depicts the distribution of potential acceptability for the 750 HAcs included in the JE frame. Their median (range) potential acceptability was 0.100 (0.009-0.880). According to potential acceptability, $96.3 \%$ of HAcs with multiple problems (1340/1392) were allocated correctly into or out of the JE frame. The threshold separating the top 750 HAcs in terms of PA was $>0.019$ in our sample.

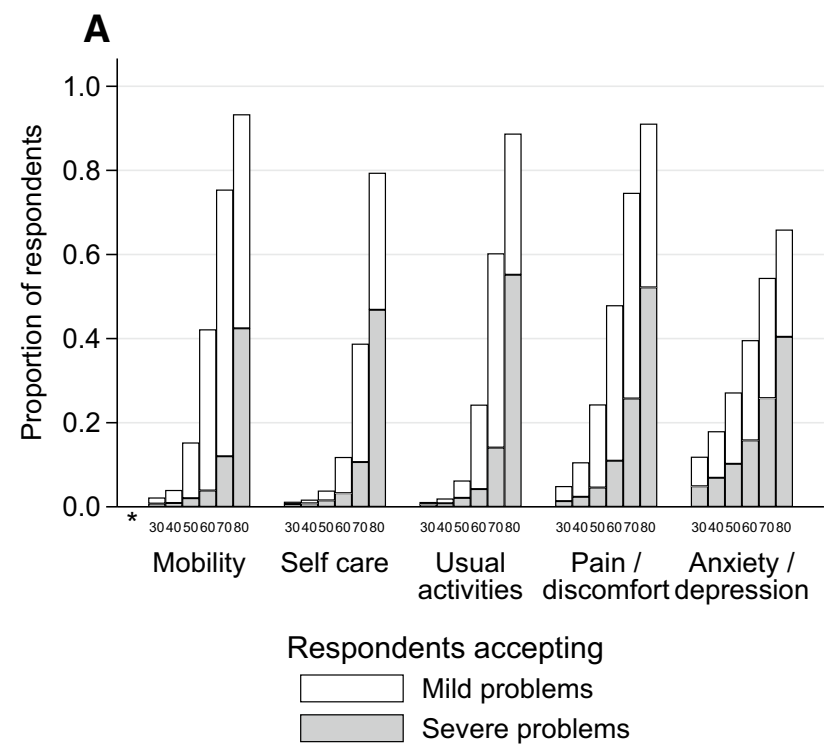

\section{Results of joint evaluation}

Those 1295 respondents participated in JE, who considered multiple problems acceptable for a given age during SE. Out of 189,346 potentially acceptable HAcs, 38,174 (20.2\%) were evaluated during JE, including 14,585 (38.2\%) direct evaluations and 23,589 (61.8\%) indirect evaluations. The average JE response set contained 11.3 direct evaluations (median: 15, range: $1-15$ ) and 18.2 indirect evaluations (median: 11, range: 0-458). Altogether 694/1375 (50.4\%) respondents performed 15 direct evaluations. On average, from each respondent, 29.5 (direct and indirect) evaluations (median: 25, range: 0-468) were included in the JE response set. From the 750 HAcs of the JE frame, 695 (92.7\%) were evaluated in JE.

\section{Estimates of conditional acceptability}

The empirical Bayes estimates of $\mathrm{CA}^{\mathrm{j}}$ included both the direct- and parametric estimate components for those 329 HAcs of the JE frame, which received 15 or more (direct or indirect) joint evaluations and altogether 95.1\% $(36,292 / 38,174)$ of JE responses. The $\mathrm{CA}^{\mathrm{j}}$ for those 421 HAcs, which had $<15$ joint evaluations were estimated only via parametric methods.

Table 2 presents the weighted OLS models that provide the parametric component of empirical Bayes estimates of $\mathrm{CA}^{\mathrm{j}}$. Due to superior fit, $\mathrm{M}_{2}$ was chosen for estimating the acceptability set. The significant overall likelihood ratio test

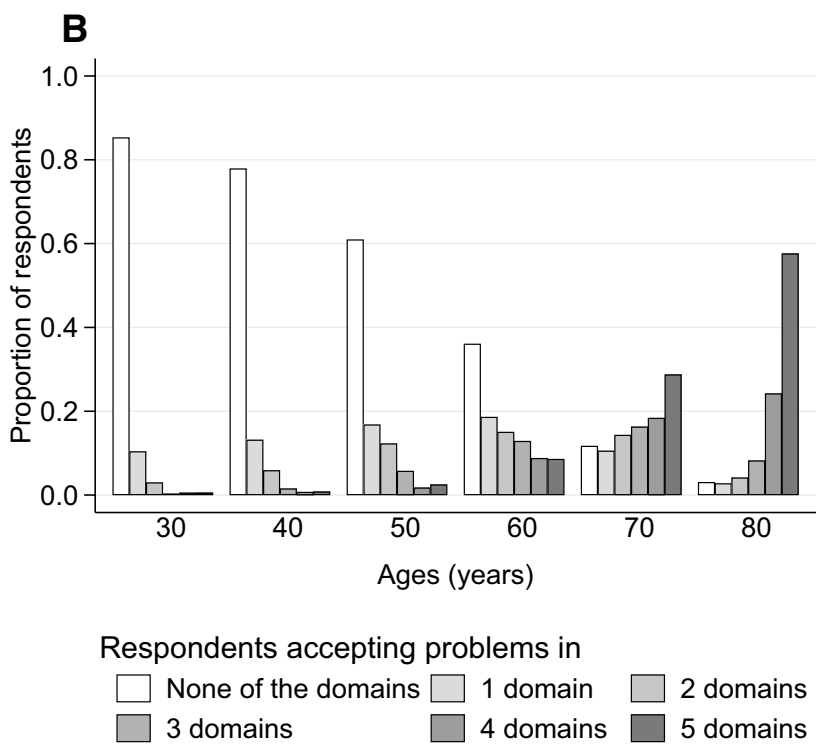

\footnotetext{
${ }^{*}$ Ages (years)
}

Fig. 3 The proportion of respondents in separate evaluation (SE) who accept problems A by EQ-5D domain and age $\mathbf{B}$ by the number domains and age 
Table 2 Regression model of conditional acceptability

\begin{tabular}{|c|c|c|c|}
\hline & & $\mathrm{M}_{1}$ & $\mathrm{M}_{2}$ \\
\hline \multirow[t]{5}{*}{ Moderate problems } & Mobility & $-0.0234 * * *(0.0071)$ & $-0.0246 * * *(0.0071)$ \\
\hline & Self-care & $-0.0272 * * *(0.0088)$ & $-0.0248 * * *(0.0090)$ \\
\hline & Usual activities & $-0.0278 * * *(0.0080)$ & $-0.0295 * * *(0.0080)$ \\
\hline & Pain / discomfort & $-0.0281 * * *(0.0082)$ & $-0.0289 * * *(0.0081)$ \\
\hline & Anxiety / depression & $-0.0628 * * *(0.0097)$ & $-0.0529 * * *(0.0102)$ \\
\hline \multirow[t]{5}{*}{ Severe problems } & Mobility & $-0.1090 * * *(0.0179)$ & $-0.1000 * * *(0.0179)$ \\
\hline & Self-care & $-0.0646 * * *(0.0193)$ & $-0.0635 * * *(0.0198)$ \\
\hline & Usual activities & $-0.0587 * * *(0.0174)$ & $-0.0597 * * *(0.0174)$ \\
\hline & Pain / discomfort & $-0.0631 * * *(0.0175)$ & $-0.0587 * * *(0.0172)$ \\
\hline & Anxiety / depression & $0.0228(0.0178)$ & $0.0188(0.0181)$ \\
\hline Any severe problem (N3) & Yes & $-0.0425 * * *(0.0116)$ & $-0.0182(0.0142)$ \\
\hline \multirow[t]{14}{*}{ Potential acceptability (PA) } & $0-0.05$ & & $-0.1010^{*}$ \\
\hline & & & $(0.0544)$ \\
\hline & $0.05-0.1$ & & -0.0535 \\
\hline & & & $(0.0340)$ \\
\hline & $0.1-0.2$ & & $-0.0858 * * *$ \\
\hline & & & $(0.0224)$ \\
\hline & $0.2-0.3$ & & $-0.0544 * * *$ \\
\hline & & & $(0.0189)$ \\
\hline & $0.3-0.4$ & & $-0.0544 * * *$ \\
\hline & & & $(0.0151)$ \\
\hline & $0.4-0.5$ & & $-0.0390 * * *$ \\
\hline & & & $(0.0144)$ \\
\hline & $0.5-0.6$ & & -0.0009 \\
\hline & & & $(0.0114)$ \\
\hline \multirow[t]{2}{*}{ Constant } & & $0.983 * * *$ & $0.9980 * * *$ \\
\hline & & $(0.0140)$ & $(0.0138)$ \\
\hline Observations & & 38,174 & 38,174 \\
\hline R-squared & & 0.081 & 0.084 \\
\hline AIC & & $42,925.66$ & $42,853.5$ \\
\hline BIC & & $43,028.26$ & $43,015.9$ \\
\hline LR-test chi2 & & & 86.2 \\
\hline Prob $>$ chi 2 & & & $<0.001$ \\
\hline
\end{tabular}

Notes: Lineal probability model estimates. Dependent variable: HAc is acceptable in JE. Observations: respondent-HAc. Robust standard errors clustered at the individual level in parentheses. Base level for potential acceptability: Range: $0.6-1$

${ }^{* * *} p<0.01, * * p<0.05, * p<0.1$ confirmed that $\mathrm{CA}^{\mathrm{j}}$ is not constant across all HAcs. The coefficients of $\mathrm{M}_{2}$ are interpreted as follows. Like the results of SE (Fig. 3A), problems in the anxiety / depression domain affected conditional acceptability differently than problems in other domains. While the coefficients for both moderate and severe problems were significant in other domains, the presence of anxiety / depression had marked effect on conditional acceptability without significant difference between severe and moderate problem levels. The presence of any severe problems (N3 term) was not significant, while lower levels of potential acceptability were associated with lower conditional acceptability.

\section{Evaluating the consistency of responses}

Due to the varying size of JE response sets, out of the 5 control questions, 5, 4, 3, 2, 1 and 0 could be evaluated by $1009(73.4 \%), 204(14.8 \%), 108(7.9 \%), 40(2.9 \%), 10$ $(0.7 \%)$ and $4(0.3 \%)$ individuals from the 1375 respondents, respectively. From the 1371 respondents who answered 1-5 control questions, only 304 (22.2\%) provided fully consistent answers, while no more than one inconsistent answer was provided by $636(46.4 \%)$. Altogether, $91.3 \%$ of the control questions were answered and $61.0 \%$ of the responses to control questions matched JE responses. JE response time was 
not an indicator of inconsistent answers. The proportion of consistent answers did not differ between the analysis sample and those respondents, who were excluded due to short JE answer times (OR 0.994, $p=0.947$ ).

\section{The EQ-5D-3L acceptability set}

The estimated EQ-5D-3L acceptability set for the 1458 HAcs is presented in Table S2 of Online Resource 7. For $30,40,50,60,70$ and 80 years of age the most acceptable HAcs and their acceptability were $11112_{30}(0.119)$, $11112_{40}(0.179), 11112_{50}(0.272), 11121_{60}(0.479), 21111_{70}$ (0.754) and $21111_{80}(0.933)$, respectively. The acceptability of $33333_{30}, 33333_{40}, 33333_{50}, 33333_{60}, 33333_{70}$ and $33333_{80}$ was $0.001,0.001,0.002,0.006,0.021$ and 0.074 , respectively.

Figure 4 displays the acceptability profiles of 12 selected health states over age. The acceptability profiles of singleproblem health states were shaped by the EQ-5D-3L domain and problem severity. However, the acceptability profiles of health states with multiple problems seemed to depend mainly on the number and severity of problems, and not on the affected domain.

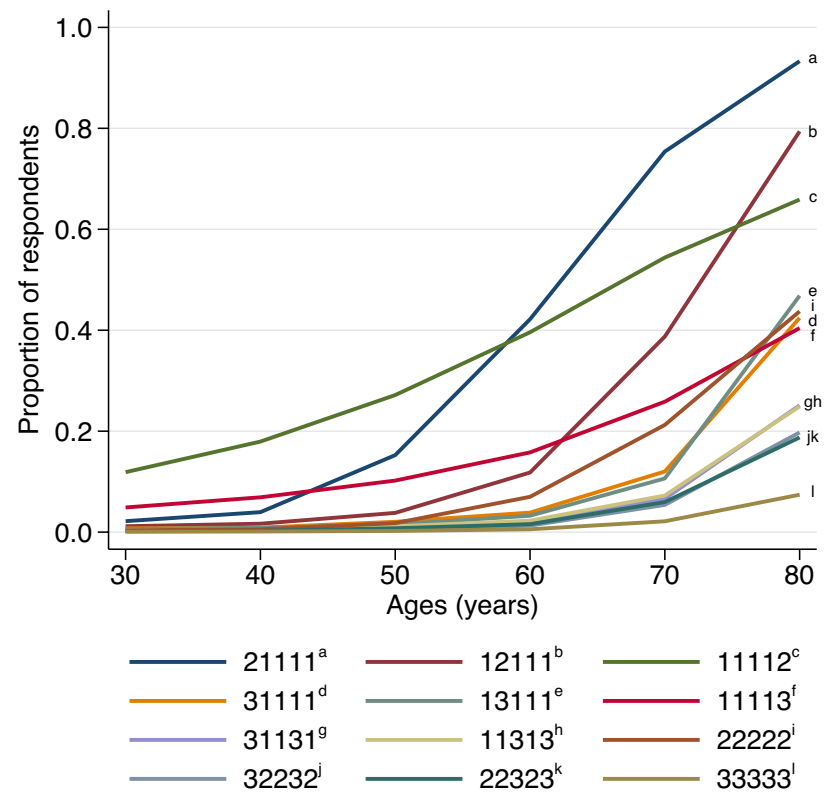

Fig. 4 Acceptability profiles of selected health states-age combinations (HAcs)

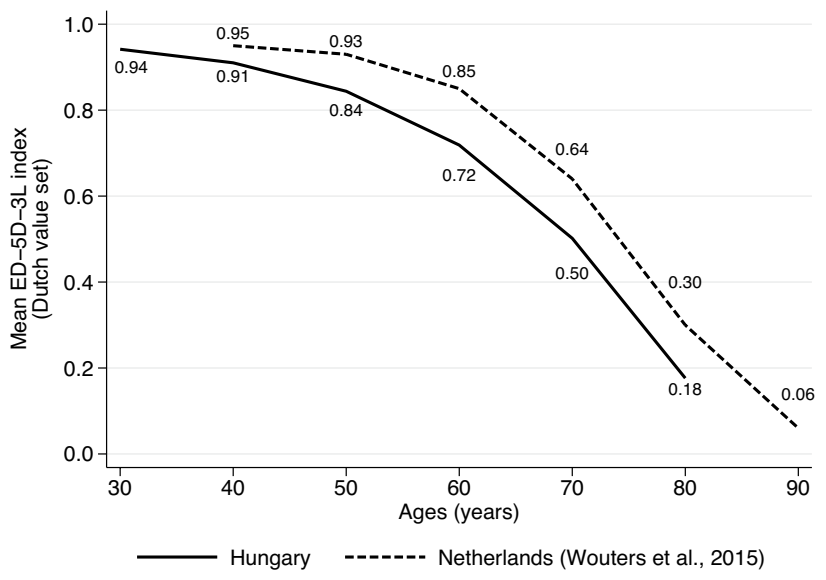

Fig. 5 Aggregate acceptable health curves $\left(\mathrm{AHC}_{\text {aggregate }}\right)$ of Hungary and the Netherlands

\section{Comparing results with previous research}

\section{Comparing Hungarian and Dutch results of separate evaluation}

Figure 5 depicts the $\mathrm{AHC}_{\text {aggregate }}$ of our sample with that of the Netherlands. Despite the similar shape of both curves, the Dutch $\mathrm{AHC}_{\text {aggregate }}$ is shifted to the right suggesting that similar levels of health problems are considered acceptable for 5-10 years older ages in the Netherlands than in Hungary. The EQ-5D-3L index differences between the two curves ranged between 0.04 and 0.14 with the greatest difference at 70 years of age. Higher $\mathrm{AHC}_{\text {aggregate }}$ values denote higher EQ-5D-3L index values (less problems) acceptable for a given age.

\section{Comparing the accuracy of the adaptive algorithm versus separate evaluation}

The overall weighted proportion of positive JE responses in our sample was 0.732 (SE: 0.012). We rejected the hypothesis that this proportion (CA) is equal to $1\left(\mathrm{~F}_{1,1294}=481.33\right.$, $\mathrm{p}<0.001$ ), confirming that separately acceptable problems are not universally acceptable when co-occurring jointly.

Figure 6 illustrates the resulting differences between acceptability and potential acceptability in case of 1392 HAcs with multiple problems. Although most respondents accepted co-occurring health problems jointly as well, acceptability was lower than PA for most HAcs, especially at ages over 50 years. The difference increased with the number and severity of health problems (represented by lower levels of PA). 
Fig. 6 Association of acceptability and potential acceptability of HAcs with multiple problems over different ages
A Age: 50 years

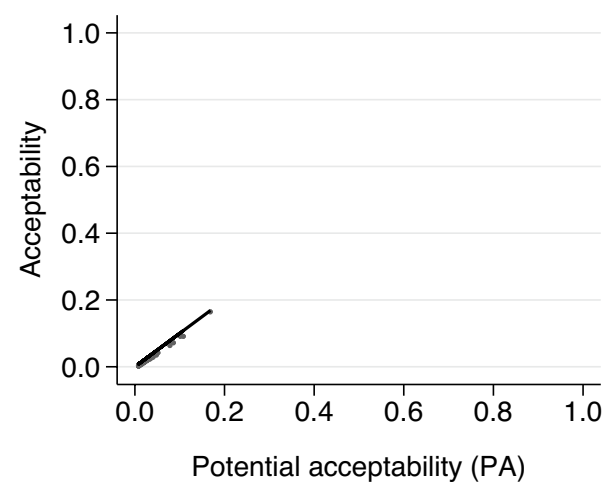

C Age years: 70

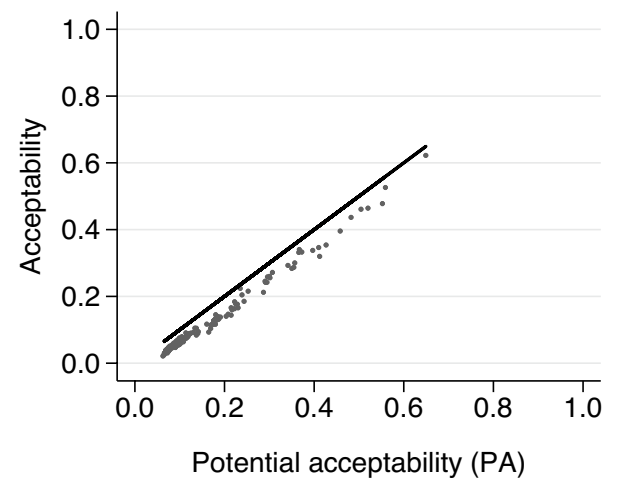

Black lines: acceptability=potential acceptability
B Age: 60 years

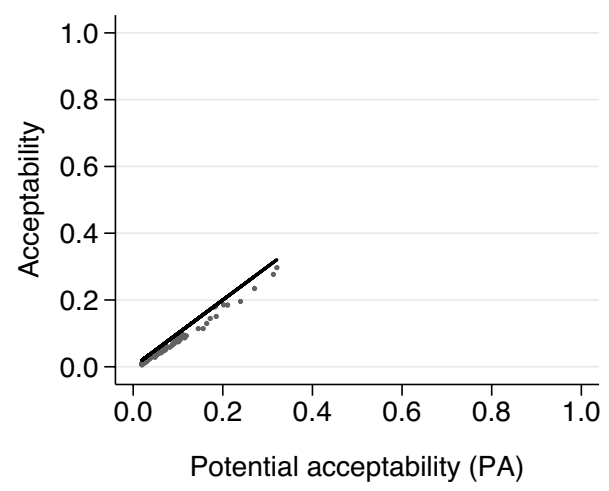

D Age: 80 years

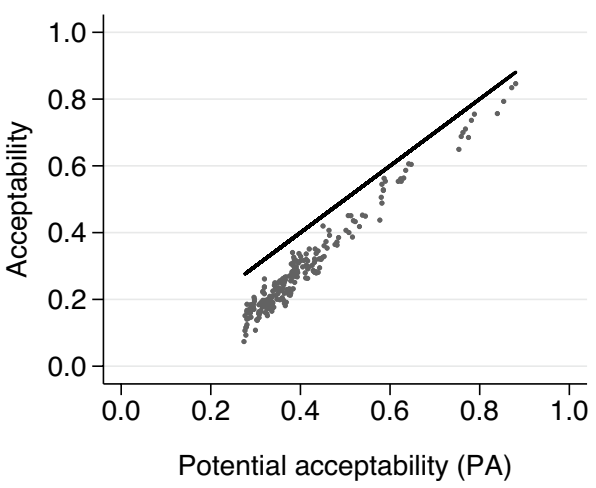

\section{Discussion}

\section{Main findings}

In this cross-sectional survey, for 1458 HAcs (243 EQ5D-3L health states in six ages from 30 to 80 years), we quantified the proportion of the general population who consider them acceptable: an acceptability set for EQ-5D-3L. We estimated acceptability via a novel adaptive survey involving joint evaluation of co-occurring problems, followed by a matching statistical measurement model. Using this method, we have shown that from those potentially acceptable HAcs that contained multiple problems, less than $3 / 4$ were acceptable in joint evaluation, depending on the age as well as the number and severity of jointly occurring health problems of HAcs.

\section{Elaboration of results}

Acceptability has previously been measured via SE both in the general population [15-17] and chronic patients [27]. Compared to that of the Hungarian population, higher
$\mathrm{AHC}_{\text {aggregate }}$ values of the Netherlands may signal higher health standards corresponding with higher life expectancy and generally healthier lifestyle $[38,39]$. $\mathrm{AHC}_{\text {aggregate }}$ values are also available from a non-representative sample of the Hungarian general population [17] and a preliminary version of the adaptive survey was tested in a small pilot study on a convenience sample [18]. Since the perception of acceptable health depends on individual characteristics of respondents, such as age, socio-economic and health status [40], more nationally representative surveys are needed to demonstrate that acceptability is a stable and reliable measure of population-level health preferences.

The strength of our study is that we determined the complete acceptability set for EQ-5D-3L in 6 ages from 30 to 80 years, which, unlike EQ-5D-3L value sets, quantifies societal preferences regarding age and the severity of disease in a structured and transparent way. The questions were designed to elicit respondents' judgements about HAcs "concerning people in general" for the six ages and not concerning themselves, reflecting the oft preferred perspective for reimbursement decisions [41]. By the secondary use of previously collected EQ-5D-3L data, the acceptability set allows the exploration 
of new health outcome measures motivated by sufficientarian theory of distributive justice. Sufficientarians assert that once individuals have secured enough, the reason to further benefit them changes. Acceptability offers a natural threshold which allows the application of different weights to acceptable versus not acceptable health states (e.g., acceptable life years, or QALY gains in unacceptable health states), which may provide a plausible equity weighting scheme that reflects societal preferences concerning age and severity of disease. The acceptability set allows the estimation of acceptability of health states as a function of utility and age, leading to a straightforward implementation in usual decision-model structures $[11,13$, 42, 43]. However, the role of acceptable health in healthcare resource allocation, its link to positive and negative utilities as well as the state of death requires further exploration.

\section{Limitations}

A limitation of our study is that despite our efforts to verify main steps of the estimation process and assess data quality, many aspects of the measurement properties of the acceptability set and its sensitivity to alternative methodological choices remained unexplored and require future research. We designed a statistical measurement model to mitigate bias arising from the dependence of survey questions on respondents' preferences, yet its statistical properties need to be explored in greater depth. Although the rate of inconsistent answers to control questions was similar to the rate of logically inconsistent answers in EQ-5D-3L valuation studies [33, 34], the exclusion criteria due to low quality of responses have not yet been established for acceptability. Based on our preliminary exploration, neither the answer times, not the control questions provided a fully reliable basis for the exclusion of potentially inconsistent respondents. For example, providing purely "yes" or "no" answers in JE may both signal strategic responses or a respondent's true preferences. Both may result in fast response times and congruent answers to control questions. Therefore, we chose to exclude respondents sparingly, only due to too brief response times to read and comprehend HAc vignettes in JE. Also, in some countries, the EQ-5D-3L population norms report flat or decreasing prevalence of problems in the anxiety / depression domain, where the assumption of monotonicity in age may have to be relaxed [24]. However, the steep increase of anxiety / depression problems with age in Hungary suggests that the assumptions of the adaptive algorithm represented adequately the experiences of the general population [24].

Another limitation was that our survey was conducted in an online population, which typically under-represents individuals with lower education or older age groups [44]. However, the Canadian EQ-5D-3L valuation study is an example that online surveys may be adequate means for health preference research [4] and the adaptive algorithm can be applied in computer-aided personal interviews [18, 45].

\section{Conclusion}

In conclusion, we quantified an acceptability set for EQ5D-3L using a novel adaptive survey algorithm and a matching statistical measurement model, which provided more accurate estimates than prior methods. However, in-depth understanding of the statistical and psychometric properties of the new method requires further research, and the potential role of acceptability in health decision-making needs to be explored.

Supplementary Information The online version contains supplementary material available at https://doi.org/10.1007/s10198-021-01424-8.

Author contributions All authors contributed to the study conception and design. Material preparation, data collection and analysis were performed by ZH, MP, LG and ZZ. Formal analysis was performed by $\mathrm{ZH}$ and $\mathrm{ZZ}$. The first draft of the manuscript was written by $\mathrm{ZZ}$ and $\mathrm{ZH}$ and all authors commented on previous versions of the manuscript. All authors read and approved the final manuscript.

Funding Open access funding provided by Óbuda University. This research has been implemented under project no. TKP2020-NKA-02 with the support provided from the National Research, Development and Innovation Fund of Hungary, financed under the Tématerületi Kiválósági Program funding scheme.

Availability of data and material Data are available upon reasonable request from the authors.

Code availability The code of statistical analyses is available upon reasonable request from the authors.

\section{Declarations}

Conflicts of interest Financial interests: In connection with writing the manuscript, $\mathrm{ZH}, \mathrm{LG}$ and $\mathrm{ZZ}$ have received financial support from project no. TKP2020-NKA-02 of the National Research, Development and Innovation Fund of Hungary, financed under the Tématerületi Kiválósági Program funding scheme at Corvinus University of Budapest. During writing this article, $\mathrm{ZZ}$ has received funding from the European Research Council (ERC) under the European Union's Horizon 2020 research and innovation programme (grant agreement No 679681). MP has received funding from Project no. 2019-1.3.1-KK2019-00007 implemented with the support provided from the National Research, Development and Innovation Fund of Hungary, financed under the 2019-1.3.1-KK funding scheme. Non-financial interests: MP is member of the EuroQol Group, a not-for-profit organisation that develops and distributes instruments that assess and value health. KNIA has no relevant financial or non-financial interests to disclose.

Ethics approval This study was approved by the Ethical Committee of the Medical Research Council of Hungary (ETT TUKEB; 3857-52019/EKU) 
Consent to participate All participants were informed and provided their consent prior completing the survey.

Consent for publication All authors have approved the final manuscript and consent for publication.

Open Access This article is licensed under a Creative Commons Attribution 4.0 International License, which permits use, sharing, adaptation, distribution and reproduction in any medium or format, as long as you give appropriate credit to the original author(s) and the source, provide a link to the Creative Commons licence, and indicate if changes were made. The images or other third party material in this article are included in the article's Creative Commons licence, unless indicated otherwise in a credit line to the material. If material is not included in the article's Creative Commons licence and your intended use is not permitted by statutory regulation or exceeds the permitted use, you will need to obtain permission directly from the copyright holder. To view a copy of this licence, visit http://creativecommons.org/licenses/by/4.0/.

\section{References}

1. Rios-Diaz, A.J., Lam, J., Ramos, M.S., Moscoso, A.V., Vaughn, P., Zogg, C.K., Caterson, E.J.: Global patterns of QALY and DALY use in surgical cost-utility analyses: a systematic review. PLoS ONE 11(2), e0148304 (2016). https://doi.org/10.1371/ journal.pone.0148304

2. Kennedy-Martin, M., Slaap, B., Herdman, M., van Reenen, M., Kennedy-Martin, T., Greiner, W., Busschbach, J., Boye, K.S.: Which multi-attribute utility instruments are recommended for use in cost-utility analysis? A review of national health technology assessment (HTA) guidelines. Eur. J. Health Econ. 21(8), 1245-1257 (2020). https://doi.org/10.1007/s10198-020-01195-8

3. EuroQoL Group: EuroQol-a new facility for the measurement of health-related quality of life. Health Policy 16(3), 199-208 (1990)

4. Xie, F., Gaebel, K., Perampaladas, K., Doble, B., Pullenayegum, E.: Comparing EQ-5D valuation studies: a systematic review and methodological reporting checklist. Med. Decis. Making 34(1), 8-20 (2014). https://doi.org/10.1177/0272989X13480852

5. Bahrampour, M., Byrnes, J., Norman, R., Scuffham, P.A., Downes, M.: Discrete choice experiments to generate utility values for multi-attribute utility instruments: a systematic review of methods. Eur. J. Health Econ. 21(7), 983-992 (2020). https://doi. org/10.1007/s 10198-020-01189-6

6. Weinstein, M.C.: A QALY is a QALY is a QALY - Or is it? J. Health Econ. 7(3), 289-290 (1988). https://doi.org/10.1016/01676296(88)90030-6

7. Dolan, P.: Modeling valuations for EuroQol health states. Med. Care 35(11), 1095-1108 (1997)

8. Gu, Y., Lancsar, E., Ghijben, P., Butler, J.R., Donaldson, C.: Attributes and weights in health care priority setting: A systematic review of what counts and to what extent. Soc. Sci. Med. 146, 41-52 (2015). https://doi.org/10.1016/j.socscimed.2015.10.005

9. Brazier, J.E., Rowen, D., Lloyd, A., Karimi, M.: Future directions in valuing benefits for estimating QALYs: is time up for the EQ-5D? Value Health 22(1), 62-68 (2019). https://doi.org/ 10.1016/j.jval.2018.12.001

10. Da, P., S, R.: The limitations of QALY: a literature review. J. Stem Cell Res. Ther. (2016). Doi:https://doi.org/10.4172/2157-7633. 1000334

11. Carlson, J.J., Brouwer, E.D., Kim, E., Wright, P., McQueen, R.B.: Alternative approaches to quality-adjusted life-year estimation within standard cost-effectiveness models: literature review, feasibility assessment, and impact evaluation. Value Health 23(12), 1523-1533 (2020). https://doi.org/10.1016/j.jval.2020.08.2092

12. Baltussen, R., Niessen, L.: Priority setting of health interventions: the need for multi-criteria decision analysis. Cost Eff. Resour. Alloc. 4, 14 (2006). https://doi.org/10.1186/1478-7547-4-14

13. Wouters, S., van Exel, N.J.A., Rohde, K.I.M., Vromen, J.J., Brouwer, W.B.F.: Acceptable health and priority weighting: Discussing a reference-level approach using sufficientarian reasoning. Soc. Sci. Med. 181, 158-167 (2017). https://doi.org/10.1016/j.socsc imed.2017.03.051

14. Shields, L.: Sufficientarianism. Philosophy. Compass 15(11), 1-10 (2020). https://doi.org/10.1111/phc3.12704

15. Brouwer, W.B., van Exel, N.J., Stolk, E.A.: Acceptability of less than perfect health states. Soc. Sci. Med. 60(2), 237-246 (2005). https://doi.org/10.1016/j.socscimed.2004.04.032

16. Wouters, S., van Exel, N.J., Rohde, K.I., Brouwer, W.B.: Are all health gains equally important? An exploration of acceptable health as a reference point in health care priority setting. Health Qual. Life Outcomes 13, 79 (2015). https://doi.org/10.1186/ s12955-015-0277-6

17. Pentek, M., van Exel, J., Gulacsi, L., Brodszky, V., Zrubka, Z., Baji, P., Rencz, F., Brouwer, W.B.F.: Acceptable health and ageing: results of a cross-sectional study from Hungary. Health Qual. Life Outcomes 18(1), 346 (2020). https://doi.org/10.1186/ s12955-020-01568-w

18. Zrubka, Z.: Az elfogadható egészségi állapotok mérésének új módszere PhD, Corvinus University of Budapest (2019)

19. Bross, F.: Acceptability Ratings in Linguistics: A Practical Guide to Grammaticality Judgments, Data Collection, and Statistical Analysis Version 1.02. . In. Mimeo, Online (2019)

20. Weskott, T., Fanselow, G.: On the informativity of different measures of linguistic acceptability. Language 87(2), 249-273 (2011). https://doi.org/10.1353/lan.2011.0041

21. Sekhon, M., Cartwright, M., Francis, J.J.: Acceptability of healthcare interventions: an overview of reviews and development of a theoretical framework. BMC Health Serv. Res. 17(1), 88 (2017). https://doi.org/10.1186/s12913-017-2031-8

22. Pentek, M., Brodszky, V., Gulacsi, A.L., Hajdu, O., van Exel, J., Brouwer, W., Gulacsi, L.: Subjective expectations regarding length and health-related quality of life in Hungary: results from an empirical investigation. Health Expect 17(5), 696-709 (2014). https://doi.org/10.1111/j.1369-7625.2012.00797.x

23. Buchholz, I., Janssen, M.F., Kohlmann, T., Feng, Y.S.: A systematic review of studies comparing the measurement properties of the three-level and five-level versions of the EQ-5D. Pharmacoeconomics 36(6), 645-661 (2018). https://doi.org/10. 1007/s40273-018-0642-5

24. Janssen, B., Szende, A., Cabases, J.: Self-reported population health: an international perspective based on EQ-5D. Selfreported population health: An international perspective based on EQ-5D. Springer, Dordrecht (NL) (2014)

25. Group, E.: Where is EQ-5D used? https://euroqol.org/eq-5dinstruments/how-can-eq-5d-be-used/where-is-eq-5d-used/ (2018). Accessed August 11, 2021

26. Lamers, L.M., McDonnell, J., Stalmeier, P.F., Krabbe, P.F., Busschbach, J.J.: The Dutch tariff: results and arguments for an effective design for national EQ-5D valuation studies. Health Econ. 15(10), 1121-1132 (2006). https://doi.org/10.1002/hec. 1124

27. Pentek, M., Rojkovich, B., Czirjak, L., Geher, P., Keszthelyi, P., Kovacs, A., Kovacs, L., Szabo, Z., Szekanecz, Z., Tamasi, L., Toth, A.E., Ujfalussy, I., Hever, N.V., Strbak, B., Baji, P., Brodszky, V., Gulacsi, L.: Acceptability of less than perfect health states in rheumatoid arthritis: the patients' perspective. 
Eur. J. Health Econ. 15(Suppl 1), S73-82 (2014). https://doi.org/ 10.1007/s10198-014-0596-2

28. Morris, C.N.: Parametric empirical bayes inference: theory and applications. J. Am. Stat. Assoc. 78(381), 47-55 (1983). https:// doi.org/10.1080/01621459.1983.10477920

29. Fisher, R.: Methods used for small area poverty and income estimation. In. Washington, (1997)

30. Akaike, H.: A new look at the statistical model identification. IEEE Trans. Autom. Control 19(6), 716-723 (1974). https://doi. org/10.1109/tac.1974.1100705

31. Schwarz, G.: Estimating the dimension of a model. Ann. Statistics (1978). https://doi.org/10.1214/aos/1176344136

32. Badia, X., Roset, M., Herdman, M.: Inconsistent responses in three preference-elicitation methods for health states. Soc. Sci. Med. 49(7), 943-950 (1999). https://doi.org/10.1016/s02779536(99)00182-3

33. Lamers, L.M., Stalmeier, P.F., Krabbe, P.F., Busschbach, J.J.: Inconsistencies in TTO and VAS values for EQ-5D health states. Med. Decis. Making 26(2), 173-181 (2006). https://doi. org/10.1177/0272989X06286480

34. Ohinmaa, A., Sintonen, H.: Inconsistencies and modelling of the Finnish EuroQoL (EQ-5D) preference values. In: Hannover EuroQoL Proceedings 1998. EuroQoL, Rotterdam

35. Tongsiri, S., Cairns, J.: Estimating population-based values for EQ-5D health states in Thailand. Value Health 14(8), 11421145 (2011). https://doi.org/10.1016/j.jval.2011.06.005

36. Yang, Z., van Busschbach, J., Timman, R., Janssen, M.F., Luo, N.: Logical inconsistencies in time trade-off valuation of EQ-5D-5L health states: Whose fault is it? PLoS ONE 12(9), e0184883 (2017). https://doi.org/10.1371/journal.pone.01848 83

37. StataCorp: Stata Statistical Software: Release 16. StataCorp LLC, College Station, TX (2019)

38. OECD, Systems, E.O.o.H., Policies: Hungary: Country Health Profile 2019. (2019)
39. OECD, Systems, E.O.o.H., Policies: Netherlands: Country Health Profile 2019. (2019)

40. Zrubka, Z., Hermann, Z., Gulácsi, L., Brodszky, V., Rencz, F., Péntek, M.: Determinants of the acceptability of health problems in different ages: exploring a new application of the EQ VAS. Eur. J. Health Econ. (2019). https://doi.org/10.1007/ s10198-10019-01060-10193

41. Rowen, D., Azzabi Zouraq, I., Chevrou-Severac, H., van Hout, B.: International regulations and recommendations for utility data for health technology assessment. Pharmacoeconomics 35(Suppl 1), 11-19 (2017). https://doi.org/10.1007/s40273-017-0544-y

42. Zrubka, Z., Brodszky, V., Péntek, M., Rencz, F., Gulácsi, L.: Pms3 - Infliximab for disease-modifying anti-rheumatic drug-naive rheumatoid arthritis patients: systematic review and descriptive analysis of publications of randomized controlled trials. Value Health 21, S288 (2018). https://doi.org/10.1016/j.jval.2018.09. 1717

43. Shields, L.: The prospects for sufficientarianism. Utilitas 24(1), 101-117 (2012). https://doi.org/10.1017/s0953820811000392

44. Eysenbach, G., Wyatt, J.: Using the Internet for surveys and health research. J. Med. Internet. Res. 4(2), E13 (2002). https://doi.org/ 10.2196/jmir.4.2.e13

45. Zrubka, Z., Gulácsi, L., Rencz, F., Brodszky, V., Péntek, M.: A new approach to assess the acceptability of health problems at different ages: an experimental study using the EQ-5D-3L instrument. Paper presented at the 35th EuroQoL Plenary Meeting, Lisbon, Portugal, 19-22nd September, 2018

46. KSH, H.C.S.O.: Microcensus 2016. https://www.ksh.hu/mikro cenzus2016/ (2017). Accessed Nov 29, 2020

Publisher's Note Springer Nature remains neutral with regard to jurisdictional claims in published maps and institutional affiliations. 